\title{
Investigation of Closed Loop Control for Interleaved Boost Converter with Ripple Cancellation Network for Photovoltaic Applications
}

\author{
Nithya Subramanian*, R. Srinivasan*, Dr.R.Seyezhai**, Pridhivi Prasanth* \& R.R. Subhesh* \\ *UG Students, Department of EEE, SSN College of Engineering, Chennai, India, 603110 \\ ** Associate Professor, Department of EEE, SSN College of Engineering, Chennai, India, 603110 \\ Email: seyezhair@ssn.edu.in
}

\begin{abstract}
Conventional sources like fossil fuels were used earlier to satisfy the energy demands. Nowadays these are being replaced by renewable sources like photovoltaic sources. Photo-voltaic is a method of generating electrical power by converting the energy from the sun into direct current with the use of semiconductor devices that exhibit photovoltaic effect. They do not cause environmental pollution and do not require any moving parts. Different types of DC-DC Converters have been proposed in literature but Inter-leaved boost Converter (IBC) is widely used because of its fast dynamic response and high power density. This paper presents an analysis of the voltage mode control strategies employed by Ripple Cancellation Network (RCN) based two phase Interleaved boost Converter (IBC) for photo-voltaic applications. After analyzing the different Boost converter topologies, the results illustrate that IBC is more efficient than conventional boost converter as it reduces the input current ripple, output voltage ripple, component size and improves its transient response. On adding the Ripple Cancellation Network to the conventional IBC, the output voltage and input current ripple are further reduced without increasing the diode current stress. Adopting the closed loop voltage mode control, the ripple components are found to decrease significantly at the output thereby achieving a higher level of efficiency. A comparison is drawn between open and closed loop voltage control ripple component values. Simulations are carried out using MATLAB/SIMULINK software to verify with the theoretical results.
\end{abstract}

Index Terms - Interleaved boost converter, photovoltaic, ripple cancellation network, voltage mode control.

\section{INTRODUCTION}

Solar energy is converted to electricity using an electronic device called solar panel using photo-voltaic effect. PV applications can be grouped into utility interactive and stand-alone applications. Utility interactive applications provide a backup system to ensure that electricity is produced throughout the year irrespective of the weather conditions. While stand-alone systems without the utility connection uses the electricity where it is produced. However, to cater to the energy needs during non-sunny and cloudy period PV-charged battery storage system is used. PV systems with batteries can be used to power dc or ac equipment. PV systems with battery storage are being used all over the world to power lights, sensors, recording equipment, switches, appliances, telephones, televisions, and even power tools. PV serves as an ideal source using the availability of low DC power requirement for mobile and remote lightning requirements [1].Systems using several types of electrical generation combine the advantages of each. Engine generators can produce electricity anytime. Thus, they provide an excellent backup for the PV modules, which produce power only during daylight hours, when power is needed at night or on cloudy days. On the other hand, PV operates quietly and inexpensively, and it does not pollute.

This paper basically presents the three converter topologies: Conventional Interleaved boost converter, Coupled inductor Interleaved boost converter and Interleaved boost converter with ripple cancellation network. It compares the performances by reducing the input current ripple, output voltage ripple and the passive component size. In conventional IBC, to make the input current ripple minimum, the inductor size increases adding to the converter weight. These shortcomings can be overcome by using the second and third converter topologies. Interleaved parallel structure has been applied in many power density applications so as to reduce the input current ripple because of its frequency doubling characteristic, output voltage ripple, passive component size and improve transient response. Coupled inductor IBC achieves ripple cancellation even more and also reduces the component size due to the coupling of inductor. However, the leakage inductance of the coupled inductor increases in the diode current stress causing extra EMI (Electro-magnetic interference) problems [2]. The third topology overcoming the above shortcomings is the interleaved boost converter with ripple cancellation network ( $\mathrm{RCN}$ ). The RCN comprises of two capacitors, two inductors and two coupled inductors. The coupled 
inductors of the network share the same core as that of the main inductors. This topology achieves maximum ripple cancellation at the input current and output voltage without introducing any extra EMI problems.

The paper (in 4 sections) initially presents the topologies of the converters (Conventional, Coupled inductor IBC and IBC with RCN) with a brief explanation on how each works. In Section-1, the topology of Ripple Cancellation Network based Interleaved boost Converter is detailed along with its operations and workings. Section-2 starts with the discussion of available control strategies for IBC and the voltage mode control strategy adopted for the proposed converter. Section -3 demonstrates the implementation of control methods for open and closed loop modes of operation. Section- 4 finally draws a comparison between the open and closed loop output voltage ripple values. As a trade-off between the converter size and ripple, the chosen number of phases is two. The converter circuit diagrams, expected waveforms, design specifications, and design parameters are discussed. The simulations for demonstrating the different topologies are done using the MATLAB/SIMULINK.

\section{IBC WiTh RIPPLE CANCELLATION NETWORK}

\section{A. Open Loop Mode}

This topology includes two capacitors, two coupled inductors and two inductors. The coupled inductors share the same core with the main inductors[3-4]. The IBC with $\mathrm{RCN}$ minimizes the input current ripple to a greater extent without introducing an extra EMI problem. The circuit of IBC with ripple cancellation network is shown in Figure1.

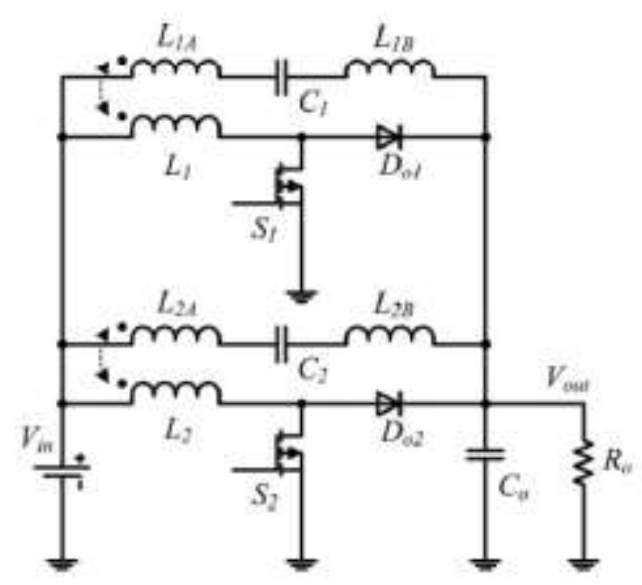

Fig. 1. Schematic of IBC with RCN

The proposed topology provides a reduced input current ripple without increasing the current stress and switching losses of the device. The operation of the proposed topology is divided into two modes of operation. In the first mode, $\left(t_{0}-t_{1}\right.$, refer fig. 2$)$ the switch $S_{1}$ is turned on and $S_{2}$ is off. The inductor $L_{1}$ is charged and the energy that is stored in $\mathrm{L}_{2}$ is transferred to the load. During the second mode $\left(\mathrm{t}_{1}-\mathrm{t}_{2}\right)$ both the switches $\mathrm{S}_{1}$ and $\mathrm{S}_{2}$ are in the off state. The inductors $\mathrm{L}_{1}$ and $\mathrm{L}_{2}$ transfer their energy to the load resulting in the decay of the inductor currents $\mathrm{iL}_{1}$ and $\mathrm{iL}_{2}$. The coupled inductor work as ripple cancellation network thereby reducing the input current ripples. The current stresses of the switches and diodes in the proposed converter are equal to the maximum inductor current value. In the interval, $t_{2}-t_{3}$, the switch $\mathrm{S}_{2}$ is turned on and the inductor $\mathrm{L}_{2}$ starts charging while $i L_{1}$ decays. During $t_{3}-t_{4}$, both $S_{1}$ and $S_{2}$ are turned off and $\mathrm{L}_{2}$ starts discharging as a result $\mathrm{iL}_{2}$ decays. The key steady waveforms for IBC with $\mathrm{RCN}$ are shown in Figure 2.

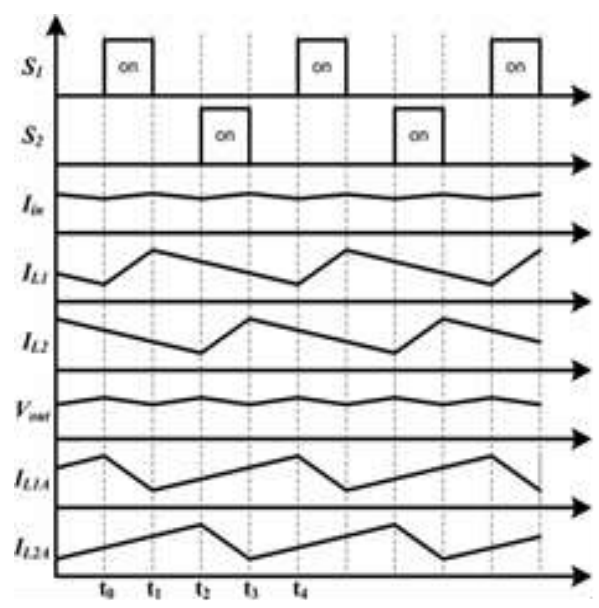

Fig. 2. Steady waveforms for IBC with RCN

The selection of duty cycle, number of phases, coupling coefficient, design of inductors and capacitors is very important for reduction of both the input current and output voltage ripple [5-6].

\section{B. Closed Loop Voltage Control Mode}

To regulate the output of the converter, closed loop control is used. Here the output voltage is given as input to the PWM generator, which in turn gives the pulses to the switches in the circuit. In order to obtain load regulation, a PI controller is added to get the desired output voltage. The block diagram is as follows,

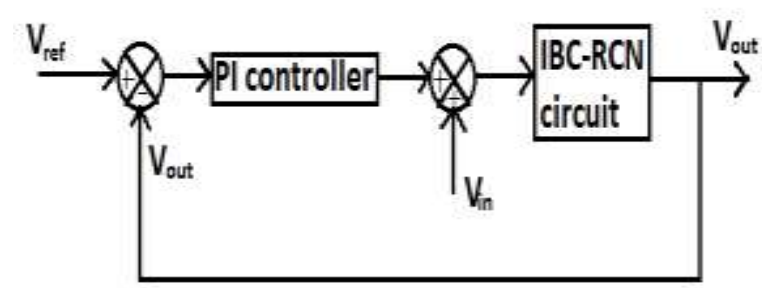

Fig. 3. Block diagram of closed loop voltage control mode

III. Design Methodologies For InTERLEAVEd Boost CONVERTER 


\section{A. Selection of Number of Phases}

The ripple content decreases with increase in number of phases. Increasing the number of phases does not decrease the ripple content to a great extent and further the circuit becomes more complex. Hence, as a trade-off between the ripple content and the cost and complexity, the number of phases is chosen as two[10-11]. The number of inductors, switches and diodes are same as the number of phases and switching frequency is same for all the phases.

\section{B. Selection of Duty Cycle}

The decision of the duty cycle is based on the number of phases. Depending upon the number of phases, the ripple is the least at a certain duty ratio. For two phase interleaved boost converter, the ripple is the least at a duty ratio of 0.45 to 0.5 . Hence, the design value of the duty ratio is chosen as 0.5 . The duty cycle $\mathrm{D}$ can be calculated by the following formula

$$
D=\frac{V_{0}-V_{i n}}{V_{0}}
$$

where $\mathrm{V}_{0}$ is the output voltage and $\mathrm{V}$ in is the input voltage.

\section{Selection of Power Devices}

The semiconductor devices chosen for constructing the two phase interleaved boost converter is MOSFET (IRFP90N20D) and a fast recovery diode (MUR 3020WT). The power MOSFET has lower switching losses and also higher switching frequency. The fast recovery diode has an advantage of ultra-fast recovery time[12-13].

The parameters chosen are $\mathrm{V}_{\text {in }}=36 \mathrm{~V}, \mathrm{~V}_{\mathrm{o}}=72 \mathrm{~V}, \mathrm{D}=0.5$, $\mathrm{F}=100 \mathrm{kHz}$ and $\mathrm{P}_{\text {out }}=1000 \mathrm{~W}$.

\section{Design of Inductance and Capacitance}

When the switch $S_{1}$ is ON, the other switch $S_{2}$ remains OFF. During this time, the main inductor $L_{1}$ is charged linearly. In the meantime, the main inductor $\mathrm{L}_{2}$ starts to transfer its energy to the load $\mathrm{R}_{\mathrm{o}}$. Similarly during the next cycle, the switch $S_{2}$ is ON and the switch $S_{1}$ remains OFF. The main inductor $\mathrm{L}_{2}$ is charged linearly and at the same time the inductor $\mathrm{L}_{1}$ starts transferring its energy to the load $\mathrm{R}_{\mathrm{o}}$.In the proposed converter, $\mathrm{L}_{1}=\mathrm{L}_{2}=\mathrm{L}$, $\mathrm{L}_{1 \mathrm{~A}}=\mathrm{L}_{2 \mathrm{~A}}=\mathrm{L}_{\mathrm{A}}, \mathrm{L}_{1 \mathrm{~B}}=\mathrm{L}_{2 \mathrm{~B}}=\mathrm{L}_{\mathrm{B}}$ and $\mathrm{M}_{1}=\mathrm{M}_{2}=\mathrm{M}$. So, the input current ripple is be expressed as

$$
\Delta_{I_{\text {in }}}=\frac{\left(M-L_{A}-L_{B}\right)\left(2 V_{\text {in }}-V_{\text {out }}\right)}{\left(M^{2}-L L_{A}-L L_{B}\right)} \frac{\left(V_{\text {out }}-V_{\text {in }}\right)}{V_{\text {out }}}
$$

The current stresses of the switches and diodes in the converter are equal to the maximum inductor current value as follows

$$
I_{L \max }=\frac{P}{V_{\text {in }}}+\frac{\Delta_{L_{L 1}}}{2}
$$

The values of $\mathrm{C}_{1}$ and $\mathrm{C}_{2}$ in the $\mathrm{RCN}$ depends on the voltage ripple of the capacitor and current ripple of the conventional IBC[9-10].With 5-10\% voltage ripple of the voltage difference between input and output on the capacitor and current ripple of the conventional IBC, the value of $\mathrm{C}_{1}$ and $\mathrm{C}_{2}$ are calculated.

Table 1. Parameter for IBC with RCN

\begin{tabular}{|l|l|}
\hline Parameters & Value \\
\hline Input Voltage, $\mathrm{V}_{\text {in }}$ & $36 \mathrm{~V}$ \\
\hline Output Voltage, $\mathrm{V}_{\mathrm{o}}$ & $72 \mathrm{~V}$ \\
\hline Output Power, $\mathrm{P}_{\text {out }}$ & $1000 \mathrm{~W}$ \\
\hline Switching Frequency, $\mathrm{F}$ & $100 \mathrm{kHz}$ \\
\hline Coupling coefficient, $\alpha$ & 0.61 \\
\hline Main inductor, $\mathrm{L}_{1}, \mathrm{~L}_{2}$ & $15 \mu \mathrm{H}$ \\
\hline Coupled inductor, $\mathrm{L}_{1 \mathrm{~A}}, \mathrm{~L}_{2 \mathrm{~A}}$ & $2 \mu \mathrm{H}$ \\
\hline Inductor, $\mathrm{L}_{1 \mathrm{~B},} \mathrm{~L}_{2 \mathrm{~B}}$ & $3.5 \mu \mathrm{H}$ \\
\hline Capacitor, $\mathrm{C}_{1}, \mathrm{C}_{2}$ & $10 \mu \mathrm{F}$ \\
\hline Output capacitor, $\mathrm{C}_{\mathrm{o}}$ & $470 \mu \mathrm{F}$ \\
\hline
\end{tabular}

\section{CONTROL StRAtegIEs For IBC With RCN}

DC-DC converters are designed to regulate the output voltage against the changes of the input voltage and load current. This leads to the requirement of more advanced control methods to meet the real demand. Many control methods are developed for the control of DC-DC converters. To obtain a control method that has the best performances under any condition is always in demand. The commonly used control methods for dc-dc converters are pulse width modulated (PWM) voltage mode control, PWM current mode control with proportional (P), proportional integral (PI), and proportional integral derivative (PID) controller. These conventional control methods like P, PI, and PID are unable to perform satisfactorily under large parameter or load variation. Therefore, nonlinear controllers came into existence. The different types of nonlinear controllers are hysteresis controller, sliding mode controller and boundary controller. But PWM is the most commonly employed control technique for DC-DC converters [7-8]. In this technique, the duration of on/off pulses of the switches are modulated to obtain a variable DC output voltage. Depending on the control principle, there are two main control strategies for choppers [9]: Time Ratio Control (TRC) and Current Limit Control (CLC).But TRC is popularly used due to its simplicity.

\section{A. Time Ratio Control}


In the time ration control, the value of the duty ration, $\mathrm{k}=\mathrm{T}_{\mathrm{ON}} / \mathrm{T}$ is varied. There are two different ways of time ratio control, constant frequency operation and variable frequency operation.

\section{a. Constant Frequency Operation}

In this control strategy, the frequency or time period $(\mathrm{f}=1 / \mathrm{T})$ is kept constant and the ON time, $\mathrm{T}_{\mathrm{ON}}$ is varied. This method is also called pulse width modulation control(PWM)[12].

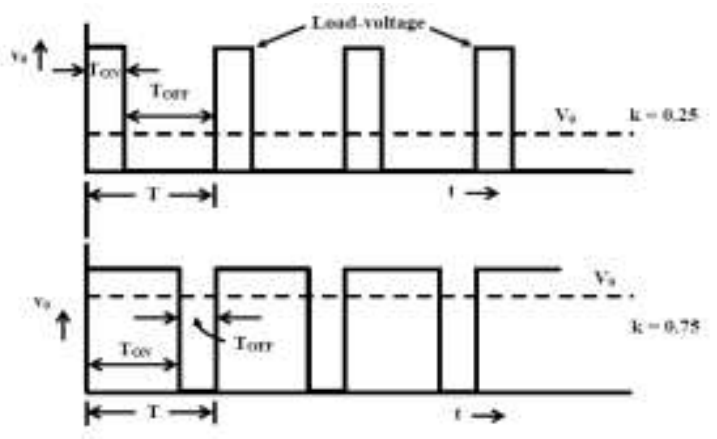

Fig. 4. Constant frequency operation

\section{b. Variable Frequency Control}

Here the frequency of time period is varied, keeping either the ON time, $\mathrm{T}_{\mathrm{ON}}$ constant or the OFF time, $\mathrm{T}_{\mathrm{OFF}}$ constant. It is also called frequency modulation control. The output voltage can be varied in both cases, with the change in duty ration, $\mathrm{k}=\mathrm{T}_{\mathrm{on}} / \mathrm{T}$.

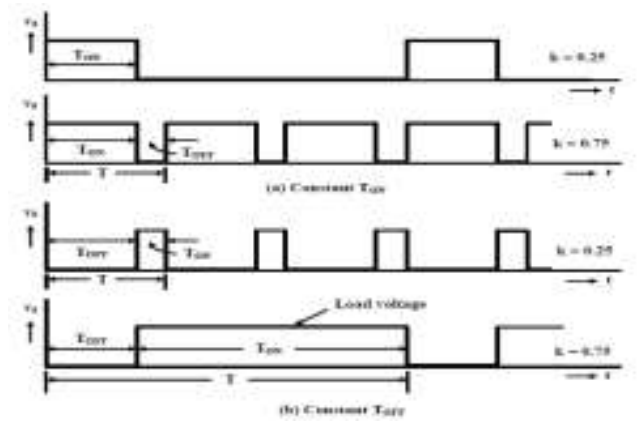

Fig. 5. Variable frequency control

The disadvantage of variable frequency control is that the filter design for wide frequency variation is difficult. Additionally, there is problem of interference with systems using certain frequencies. The large OFF time in frequency modulation technique, may make the load current discontinuous, which is undesirable. As a result, the constant frequency control (PWM) is preferred for dcdc converters.

Depending on the control signal required to achieve PWM, there are two modes of operation: Voltage mode PWM \& Current mode PWM techniques. This paper focuses on voltage mode PWM. In PWM technique, a reference signal is generated and it is compared with a carrier triangular waveform. Whenever, the reference signal is greater than the carrier, an ON pulse is generated. The chopping frequency is determined by the frequency of the carrier waveform irrespective of the operating conditions.

Voltage-mode control (VMC) is widely used because it is easy to design and implement, and has good community to disturbances at the reference input. The voltage feedback arrangement is known as voltage-mode control when applied to dc-dc converters. VMC only contains single feedback loop from the output voltage. The basic three stages in VMC are : the output stage consisting of the output filter, the modulator gain and the voltage loop compensation. Voltage mode derives its control signal from the output voltage of the switching converter. The block diagram for the open loop system for DC-DC converter is shown in Fig.6.

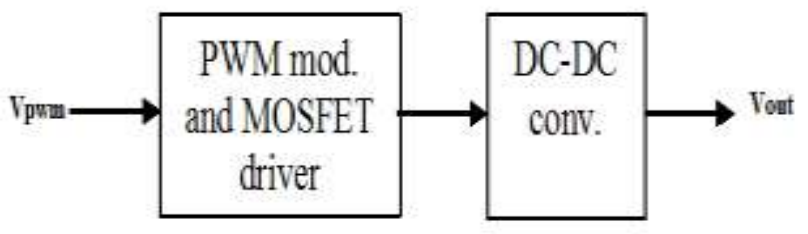

Fig. 6. Block diagram of open loop system

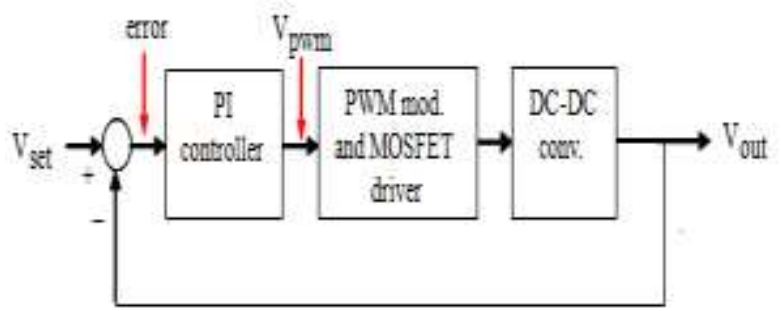

Fig. 7. Block diagram of voltage mode control system

In VMC, the error amplifier compares the actual output voltage with the reference voltage and generates an error voltage. This voltage is fed to the comparator which compares this signal with the carrier signal to generate an on/off pulse. The output is high only when the error voltage is higher than the carrier signal. This PWM signal is used for driving the power devices as shown in Fig.8.
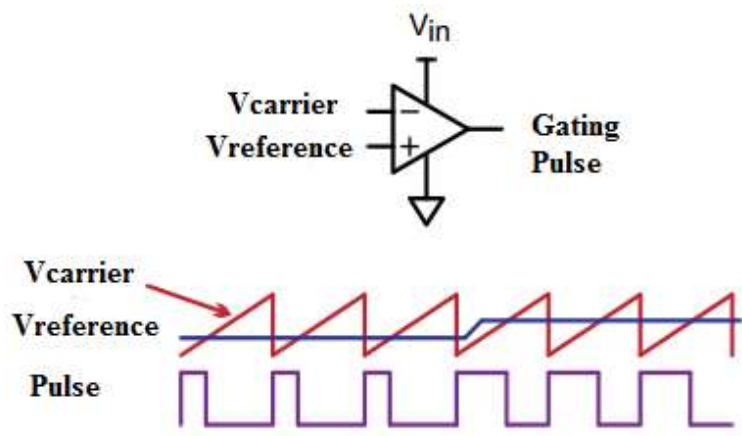

Fig. 8. Generation of PWM pulse

Moreover, VMC has the following advantages:

- Consists of single feedback loop making the circuit design easy and simple. 
- Use of a large-amplitude carrier waveform provides a good noise margin for a stablemodulation process.

- A low-impedance power output providing better cross-regulation for multiple-output supplies.

The main drawback in this closed loop scheme is that with line regulation the output settles slowly due to the error amplifier.

\section{Simulation Results}

Based on the simulation parameters, the proposed converter is simulated in open loop and closed operation and the results are presented below: The output waveform for IBC with RCN was observed as shown in Fig.9.

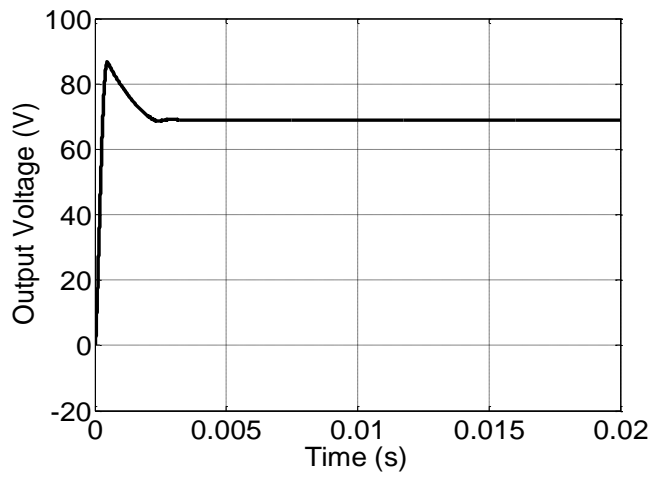

Fig. 9. Output voltage of open loop IBC-RCN

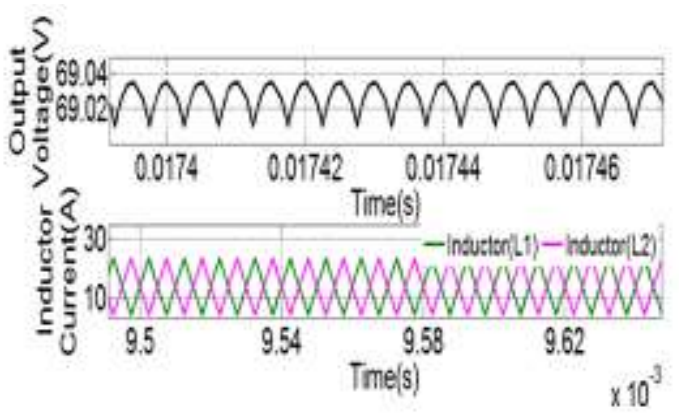

Fig. 10. Output voltage ripple and inductor current waveforms

From the above waveform, the output voltage ripple was found as $0.03 \%$.

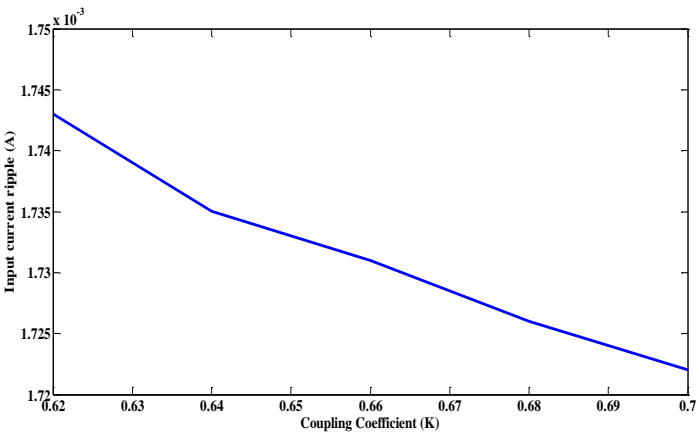

Fig. 11a. Input current ripple Vs. Coupling Coefficient (K)
Fig.11a shows that the input current ripple reduces as the coupling coefficient increases [14-17] and for this work, the value of $\mathrm{K}$ is chosen as 0.61 .

Voltage mode PWM control technique is implemented for the proposed IBC with the reference voltage of $69 \mathrm{~V}$ and the result is shown in Fig.11b.

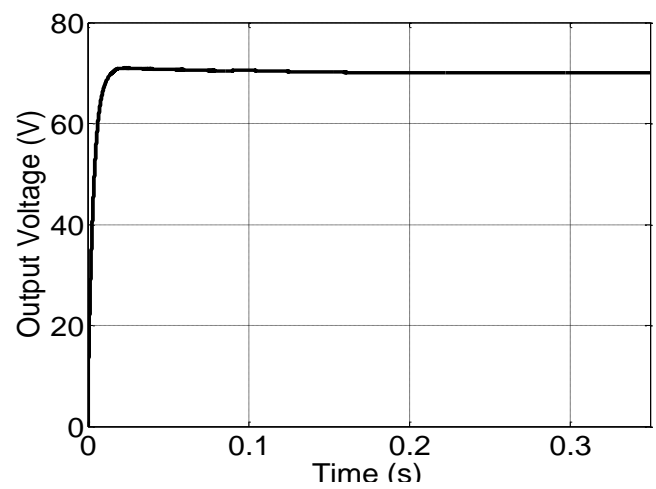

Fig. 11b. Output voltage of closed loop IBC-RCN

With closed loop control, the output voltage ripple is computed and compared with open loop system. With VMC, the output voltage ripple is reduced for the proposed converter as shown in Table.2.

Table 2. Comparison of Voltage ripple

\begin{tabular}{|l|l|l|}
\hline Parameter & Open loop & Closed loop \\
\hline $\begin{array}{l}\text { Output voltage } \\
\text { ripple }\end{array}$ & $1.0 \mathrm{~V}$ & 0.009 \\
\hline
\end{tabular}

From the above table, it can be inferred that the output voltage ripple is minimum in the closed loop system.

\section{LOAD REGULATION}

The VMC scheme is tested for various values of the load resistance and it is found that with closed loop control the output of the proposed IBC is regulated. Figs. $12 \& 13$ shows the load voltage and current under open loop and closed loop control .

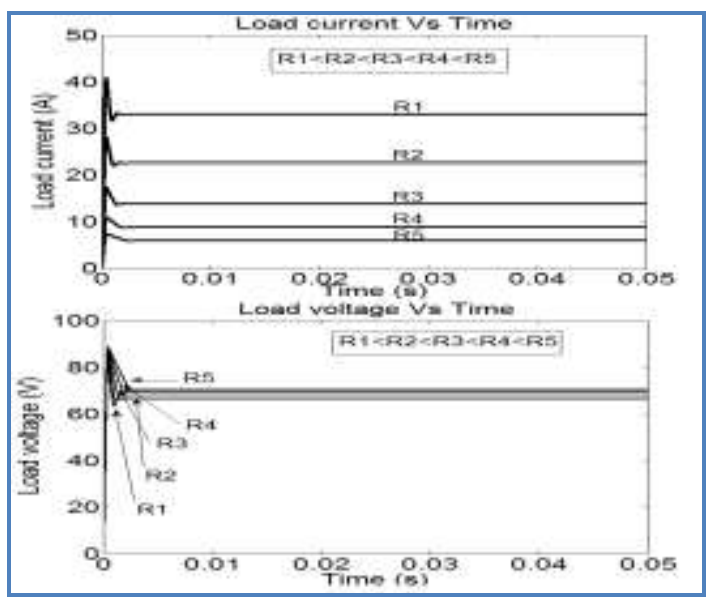

Fig. 12. Load voltage \& current under open loop 


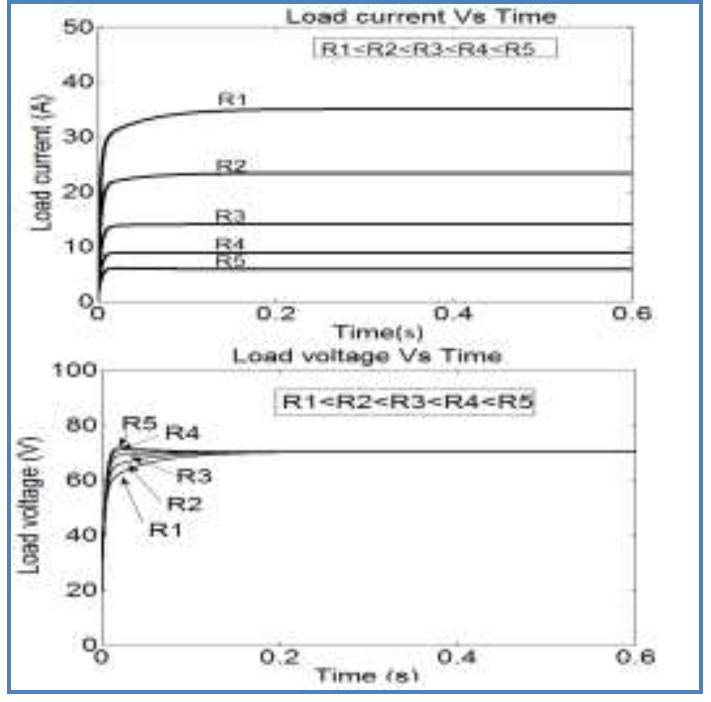

Fig. 13. Load voltage \& current under closed loop

From the above graphs, it can be inferred that the closed loop voltage control mode achieves constant output voltage for different load values. Additionally, the transient at the initial period is eliminated using closed loop control.

\section{CONCLUSION}

This paper has discussed about the different control strategies for IBC that can be used for photovoltaic applications. From the results, it is observed that on adding Ripple Cancellation Network to Interleaved Boost Converter, higher level of ripple cancellation is achieved at the input current and output voltage for a duty cycle of 0.5(two-phase) in comparison to conventional boost converter due to its fast dynamic response and high power density. Moreover, it has been recorded that ripple reduction at the input and output is greater in closed loop voltage mode when compared to open loop operation. The output voltage ripple in closed loop control scheme is found to be $0.009 \mathrm{~V}$ and the open loop mode is $1.031 \mathrm{~V}$. Higher stability levels are attained using closed loop voltage control as load regulation is achieved. Therefore, the proposed IBC with RCN achieves maximum ripple cancellation and higher stability with the constant frequency control scheme. Hence, closed loop voltage control of RCN based IBC proves to be a suitable topology for photovoltaic applications.

\section{REFERENCES}

[1] M. R. Feyzi, S. A. KH. MozaffariNiapour,F. Nejabatkhah, A. Feizi. "Brushless DC Motor Drive Based On MultiInput DC Boost Converter Supplemented By Hybrid PV/FC/Battery Power System", IEEE Journal, volume, IEEE CCECE 000442 (2011).

[2] Wuhua Li, Jianguo Xiao, Jiande Wu, Jun Liu, Xiangning He. "Application Summarization of Coupled Inductors in DC/DC Converters", IEEE Journal, volume, pp. 14871491, (2009).

[3] Guangyong Zhu, Brent A. McDonald, Kunrong Wang. "Modeling and Analysis of Coupled Inductors in Power
Converters", IEEE Journal, volume, pp. 1355 - 1363, (2011).

[4] Ishtiyaq Ahmed Makda, Morten Nymand . "Differential Mode EMI Filter Design for Ultra High Efficiency Partial Parallel Isolated Full-Bridge Boost Converter", IEEE Journal, volume, 978-1-4673-1792-4/13, (2013).

[5] Kenta Isozumi, Noriyuki Kimura , C. D. ToshimitsuMorizane, Hideki Omori. "Soft Switching DCDC Converter with Coupling Inductor for Continuos Current Mode Operation", IEEE Journal

[6] R.Seyezhai. "Design Consideration of Interleaved Boost Converter for Fuel Cell Systems", IJA EST, volume, pp.323 - 329.(2011)

[7] Saggini S., Mattavelli P., Ghioni M. and Redaelli M., Mixed-Signal Voltage-Mode Control for DCand\#x2013;DC Converters With Inherent Analog Derivative Action, Power Electronics, IEEE Transactions on, 23, 1485-1493.

[8] Mohan N., Undeland T. M. and Robbins W. P., Power Electronics - Converters, Applications, and Design (3rd Edition), ed: John Wiley and Sons.

[9] Rashid M.H., Power Electronics: Circuits, Devices and Applications vol. (3rd Edition), Prentice Hall (2003)

[10] R. Seyezhai, B. L. Mathur. "A Comparison of ThreePhase Uncoupled and Directly Coupled Interleaved Boost Converter for Fuel Cell Applications", IJEEI Journal, volume,3, (2011).

[11] Yan Dong, Fred. C. Lee, Ming Xu. “ Evaluation of Coupled Inductor Voltage Regulators", IEEE Journal, volume, pp. 831 - 837, (2008).

[12] Yu Gu, Donglai Zhang "Interleaved Boost Converter with Ripple Cancellation Network", IEEE Journal, volume, pp.3860 - 3869, (2013).

[13] Robert S. Balog, Philip T. Krein, "Coupled- Inductor Filter: A Basic Filter Building Block", IEEE Journal, volume, pp. $537-546$, (2013).

[14] Sathya, P.; Natarajan, R., 'Design and Implementation of 12/24V Closed loop Boost Converter for Solar Powered LED lighting system, International Journal of Engineering Science \&Technology, volume 5 issue 2, February 2013.

[15] Farag. S. Alargt; Ahmed. S. Ashur, 'Analysis and Simulation of Interleaved Boost Converter for Automotive Applications', International Journal of Engineering and Innovation Technology, volume 2, issue 11, May 2013.

[16] TamalBiswas, G KPanda, P KSaha, S Das, "Design of PWM-Based Sliding-Mode Control of Boost Converter with Improved Performance", International Journal of Advanced Research in Electrical, Electronics and Instrumentation Engineering, Vol. 4, Issue 2, February 2015.

[17] M.T. Makhloufi, M.S. Khireddine, Y. Abdessemed, A. Boutarfa, "Tracking Power Photovoltaic System using Artificial Neural Network Control Strategy", International Journal of Intelligent Systems and Applications(IJISA), IJISA Vol. 6, No. 12, November 2014. 


\section{Author's profile}

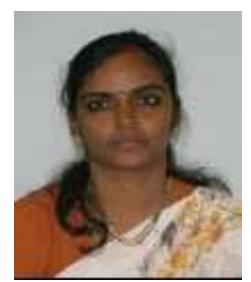

Dr.R.Seyezhai obtained her B.E.

(Electronics \&Communication Engineering) from Noorul Islam College of Engineering, Nagercoil in 1996 and her M.E in Power Electronics \& Drives from Shanmugha College of Engineering, Thanjavur in 1998 and Ph.D from Anna University, Chennai, in 2010.She has been working in the teaching field for about 16 Years. She has published 150 papers in the area of Power Electronics \& Drives. Her areas of interest include SiC Power Devices \& Multilevel Inverters.

How to cite this paper: Nithya Subramanian, R. Srinivasan, R.Seyezhai, Pridhivi Prasanth, R.R. Subhesh,"Investigation of Closed Loop Control for Interleaved Boost Converter with Ripple Cancellation Network for Photovoltaic Applications", IJITCS, vol.7, no.9, pp.66-72, 2015. DOI: 10.5815/ijitcs.2015.09.10 